\title{
Correction to: Health Care Provider Perceptions of Caring for Individuals with Inherited Pancreatic Cancer Risk
}

Meghan L. Underhill ${ }^{1} \cdot$ Rachel Pozzar $^{1} \cdot$ Daniel Chung $^{2} \cdot$ Mandeep Sawhney $^{3} \cdot$ Matthew Yurgelun $^{1}$

Published online: 17 December 2019

(C) American Association for Cancer Education 2019

\section{Correction to: Journal of Cancer Education} https://doi.org/10.1007/s13187-019-01623-1

The original version of this article unfortunately contained a mistake. The name of "Matthew Yurgelun" is now corrected in the author group of this article.

The online version of the original article can be found at https://doi.org/ 10.1007/s13187-019-01623-1

Meghan L. Underhill

meghanl_underhill@dfci.harvard.edu

1 Dana-Farber Cancer Institute, 450 Brookline Ave, LW522, Boston, MA 02215, USA

2 Massachusetts General Hospital, Boston, USA

3 Beth Israel Deaconess Medical Center, Boston, USA 